\title{
Myocardial Revascularization with Coronary Endarterectomy. Stratification of Risk Factors for Early Mortality
}

\author{
Fernando Antibas A tik, Luís Alberto O liveira Dallan, Sérgio A Imeida de 0 liveira, \\ Luiz Augusto Ferreira Lisboa, Fernando Platania, Richard Halti Cabral, Adib Domingos Jatene
}

São Paulo, SP - Brazil

\begin{abstract}
Objective - To determine the risk factors for mortality related to myocardial revascularization when performed in association with coronary endarterectomy.
\end{abstract}

Methods - We assessed retrospectively 353 patients who underwent 373 coronary endarterectomies between January '89 and November '98, representing 3.73\% of the myocardial revascularizations in this period of time. The arteries involved were as follows: right coronary artery in 218 patients (58.45\%); left anterior descending in 102 patients (27.35\%); circumflex artery in 39 patients (10.46\%); and diagonal artery in 14 patients (3.74\%). We used 320 (85.$79 \%)$ venous grafts and $53(14.21 \%)$ arterial grafts.

Results - In-hospital mortality among our patients was $9.3 \%$ as compared with $5.7 \%$ in patients with myocardial revascularizations without endarterectomy $(p=0.003)$. Cause of death was related to acute myocardial infarction in $18(54.55 \%)$ patients. The most significant risk factors for mortality identified were as follows: diabetes mellitus ( $p=0.001$; odds ratio $=7.168$ ), left main disease (<0.001; 9.283), female sex (0.01; 3.111), acute myocardial infarction $(0.02 ; 3.546)$, ejection fraction $<35 \%(<0.001 ; 5.89)$, and previous myocardial revascularization $(<0.001 ; 4.295)$.

Conclusion - Coronary endarterectomy is related to higher mortality, and the risk factors involved are important elements of a poor outcome.

Key words- coronary endarterectomy, myocardial revascularization, atherosclerosis

Instituto do Coração do Hospital das Clínicas - FMUSP

Mailing address: Fernando Antibas Atik - Av. Chibarás, 626/101 - 04076-003 São Paulo-SP, Brazil

English version by Stela Maris C. e Gandour
Coronary endarterectomy as proposed by Bailey et al ${ }^{1}$ has been used since 1957 as a form of myocardial revascularization. Currently, marked technological developments have changed cardiac surgery and have reduced the unsuccessful indices of myocardial revascularization discarding coronary endarterectomy as a possible treatment for coronary heart disease for some decades, because of its high morbidity and mortality.

On the other hand, a great increase in surgical indications has occurred for individuals of more advanced ages with diffuse coronary heart disease, whose lesions were frequently considered inoperable through conventional methods. The need for complete myocardial revascularization in these patients has justified the resurgence of coronary endarterectomy ${ }^{2}$.

Because of the difficulty in defining precisely the ideal patients to undergo coronary endarterectomy, which results in a variability of indications and occasionally in its indiscriminate use, coronary endarterectomy has been characterized as a risk factor of mortality associated with myocardial revascularization ${ }^{3}$, mainly related to perioperative acute myocardial infarction. Therefore, the use of coronary endarterectomy is still a matter of controversy and its results are highly variable due to lack of uniformity.

The objective of this study is to assess the in-hospital evolution of patients undergoing this procedure and to determine the risk factors related to its morbidity and mortality.

\section{Methods}

We assessed retrospectively 353 patients who had undergone coronary endarterectomy during the period from 1989 to 1998 at the Instituto do Coração of Hospital das Clínicas, School of Medicine, University of São Paulo, corresponding to $3.73 \%$ of the 9,429 surgeries for myocardial revascularization performed at this institution during that 
period. Ages of the patients ranged from 29 to 84 years (mean of 59.8 years), and $276(78.19 \%$ ) patients were males.

Of all patients, 171 (48.44\%) had 3 or more risk factors for coronary heart disease and 138 (39.09\%) were diabetic patients. Surgical indication resulted from unstable angina in $190(53.82 \%)$ patients, and $197(55.81 \%)$ patients were in functional class III or IV of the Canadian Cardiovascular Society. Fifty-seven (16.15\%) patients were operated on during the acute phase of acute myocardial infarction.

Twenty-four (6.8\%) patients were operated upon on an emergency basis. Previous acute myocardial infarction and myocardial revascularization occurred, respectively, in 179 $(50.71 \%)$ and $27(7.6 \%)$ patients. Triple vessel involvement occurred in $323(91.5 \%)$ patients, and $47(13.31 \%)$ patients had left main disease. Ventricular function was significantly impaired (ejection fraction $<35 \%$ ) in $51(14.45 \%$ ) patients.

All patients underwent surgery with extracorporeal circulation. The methods of cardiac protection used were intermittent aortic clamping with mild hypothermia in 204 (57.8\%) patients and cold blood cardioplegia in the remaining patients. The manual technique of endarterectomy was adopted through a wide arteriotomy and removal of thrombi proximal and distal to the opening. In cases of arteriotomies larger than $3 \mathrm{~cm}$, reconstruction was performed through wide venous anastomoses or through arterioplasty with the saphenous vein followed by an anastomosis with arterial graft at the center of the venous fragment.

We performed 373 endarterectomies, and the procedure was performed twice in 20 patients. The arteries operated upon were the following: right coronary artery in 218 (58.45\%) patients; left anterior descending artery in 102 $(27.35 \%)$ patients; circumflex artery and its branches in 39 $(10.46 \%)$ patients; and diagonal artery in $14(3.74 \%)$ patients. We used the saphenous vein graft in $320(85.79 \%)$ patients, the left internal thoracic artery graft in $39(10.46 \%)$ patients, the right internal thoracic artery graft in $11(2.95 \%)$ patients, the right gastroepiploic artery graft in $2(0.55 \%)$ patients, and the radial artery graft in one $(0.26 \%)$ patient.

We performed a mean of 3.32 anastomoses per patient. The mean durations of extracorporeal circulation and anoxia were, respectively, 116.27 and 71.95 minutes.

The most frequently associated procedure was left ventricular aneurysmectomy in 21 patients, and we added thrombectomy in 11 patients. The other procedures associated were left ventricular thrombectomy in 9 patients, mitral valvoplasty in 5 patients, aortic valve replacement in 4 patients, mitral valve replacement in 3 patients, carotid endarterectomy in 2 patients, replacement of the ascending aorta in 2 patients, correction of a fistula between the right coronary artery and the pulmonary artery in one patient, and pulmonary lobectomy in one patient.

In the postoperative period, characterization of acute myocardial infarction followed basically electrocardiographic criteria, such as new $\mathrm{Q}$ waves, persistent intraventricular conduction defects, and poor of progression of the $\mathrm{R}$ wave in precordial leads. In addition, changes in regional contraction on the two-dimensional echocardiogram that did not exist in the preoperative period were also considered. Measurement of MB fraction of the creatine phosphokinase, even though a routine procedure in the immediate postoperative period, did not constitute an absolute criterion for acute myocardial infarction, acting as a guide for this diagnosis when its value was $10 \%$ greater than that of total creatine kinase.

From the first postoperative day on, all patients received $200 \mathrm{mg} /$ day of acetylsalicylic acid until hospital discharge. Patients receiving arterial grafts were treated with calcium channel blockers (diltiazem $-180 \mathrm{mg} /$ day) from the first postoperative day on.

We tried to study the possible predictive factors of inhospital death initially through a univariate analysis using the following tests: chi-square test, Pearson's test, Fisher's exact test, Student's $t$ test, and Wilcoxon test. To estimate the probability of in-hospital death considering the variables selected in the univariate analysis, through a multivariate model, we used the logistic regression technique. The significance level established was 0.05 .

\section{Results}

In-hospital mortality was $9.35 \%$ (33 patients) as compared with $5.66 \%$ of the remaining myocardial revascularizations $(\mathrm{p}=0.003)$. The cause of death was related to perioperative acute myocardial infarction with cardiogenic shock in $18(54.55 \%)$ patients. Intraaortic balloon was used in 46 $(13.03 \%)$ patients. Acute myocardial infarction and arrhythmias in the postoperative period occurred in $48(13.6 \%)$ and $100(28.33 \%)$ patients, respectively. Twenty-three (6.52\%) patients had to be reoperated upon and the causes were as follows: mediastinal bleeding in 15 patients, 9 of whom also had associated cardiac tamponade; acute myocardial infarction in 3 patients; cardiopulmonary arrest in 2 patients; and mediastinitis in the 3 remaining patients.

To define the risk factors for mortality, the patients were divided into 2 groups as follows: group 1 - comprising 320 patients who survived the surgical procedure and were discharged from the hospital; group 2 - comprising 33 patients who evolved to in-hospital death.

The univariate analysis of the risk factors for mortality (Table I) identified the following characteristics as statistically significant: female gender $(\mathrm{p}=0.01)$, diabetes mellitus $(\mathrm{p}=0.001)$, previous myocardial infarction $(\mathrm{p}=0.022)$, previous myocardial revascularization $(p<0.001)$, surgeries performed during the acute phase of myocardial infarction $(\mathrm{p}=0.02)$, left main disease $(\mathrm{p}<0.001)$, ejection fraction $<35 \%$ $(\mathrm{p}<0.001)$, and a longer extracorporeal circulation $(\mathrm{p}=0.005)$. In the postoperative period, the following risk factors for mortality were identified: use of intraaortic balloon ( $\mathrm{p}<0.0$ $01)$, presence of arrhythmias $(\mathrm{p}=0.001)$, perioperative acute myocardial infarction $(\mathrm{p}<0.001)$, acute renal failure $(\mathrm{p}<0.001)$, reoperation $(\mathrm{p}<0.001)$, and a shorterhospitalization $(\mathrm{p}=0.001)$.

Other variables, such as age, the presence of three or more risk factors for coronary heart disease, triple vessel lesions, number of grafts used in revascularization, double endarterectomy, emergency operation, associated proce- 


\begin{tabular}{|c|c|c|c|}
\hline \multicolumn{4}{|c|}{$\begin{array}{c}\text { Table I - Risk factors for preoperative mortality related to coronary } \\
\text { endarterectomy through univariate analysis }\end{array}$} \\
\hline Variable & Group 1 & Group 2 & $P$ \\
\hline $\mathrm{N}$ & 320 & 33 & - \\
\hline Age (years) & 59.75 & 60.7 & 0.587 \\
\hline Female sex & $64(20)$ & $13(39.39)$ & $0.010 *$ \\
\hline Diabetes mellitus & $116(36.25)$ & $22(66.67)$ & $0.001 *$ \\
\hline Risk factors $* *$ & $151(47.19)$ & $20(60.61)$ & 0.142 \\
\hline Previous AMI & $156(48.75)$ & $23(69.7)$ & $0.022 *$ \\
\hline Previous MR & $20(6.25)$ & $7(21.21)$ & $<0.001 *$ \\
\hline AMI & 47 (14.69) & $10(30.3)$ & 0.020 * \\
\hline Triple vessel & $259(80.94)$ & $27(81.82)$ & 0.902 \\
\hline LM & $37(11.56)$ & $10(30.3)$ & $<0.001 *$ \\
\hline $\mathrm{EF}<35 \%$ & $37(11.56)$ & $14(42.42)$ & $<0.001 *$ \\
\hline Emergency & $21(6.56)$ & $3(9.1)$ & 0.583 \\
\hline \multicolumn{4}{|c|}{$\begin{array}{l}\text { Data between parentheses are percentages; * - statistically significant } \\
\text { data; ** - three or more risk factors for coronary heart disease; AMI- } \\
\text { acute myocardial infarction; MR- myocardial revascularization; LM left } \\
\text { main disease; EF- ejection fraction. }\end{array}$} \\
\hline
\end{tabular}

dures, duration of anoxia, and duration of the intensive care unit stay were also studied in the univariate analysis, but they did not reach statistical significance (Table II).

To select the most important variables for assessing the probability of death, we used multivariate analysis, which identified the following preoperative risk factors (Table III): female gender, diabetes mellitus, disease left main, patients undergoing surgery in the acute phase of myocardial infarction, previous myocardial revascularization, and ejection fraction $<35 \%$.

No statistically significant relation was found between the artery undergoing endarterectomy and the use of the intraaortic balloon pump the presence of arrhythmias, perioperative acute myocardial infarction, and death (Table IV). We also found no relation between the type of graft used in the artery undergoing endarterectomy and the above-cited variables (Table V).

\begin{tabular}{|c|c|c|c|}
\hline \multicolumn{4}{|c|}{$\begin{array}{l}\text { Table II - Operative and postoperative risk factors for mortality } \\
\text { related to coronary endarterectomy through univariate analysis }\end{array}$} \\
\hline Variable & Group 1 & Group 2 & $\mathrm{P}$ \\
\hline Number of grafts/pt & 3.33 & 3.18 & 0.531 \\
\hline Double CE & $18(5.63)$ & $2(6.06)$ & 0.695 \\
\hline Associated procedure & $42(13.13)$ & $6(18.18)$ & 0.420 \\
\hline ECC duration (min) & 114.25 & 135.85 & $0.005 *$ \\
\hline Duration of anoxia (min) & 71.53 & 75.97 & 0.209 \\
\hline Intraaortic balloon & $24(7.5)$ & $24(72.73)$ & $<0.001 *$ \\
\hline Arrhythmias & $88(27.5)$ & $29(87.88)$ & $0.001 *$ \\
\hline Perioperative AMI & $32(10)$ & $18(54.55)$ & $<0.001 *$ \\
\hline ARF & $20(6.25)$ & $15(45.45)$ & $<0.001 *$ \\
\hline Reoperation & $11(3.44)$ & $12(36.36)$ & $<0.001 *$ \\
\hline Hospitalization (days) & 9 & 4 & $0.001 *$ \\
\hline ICU stay (days) & 4.35 & 11.39 & 0.257 \\
\hline \multicolumn{4}{|c|}{$\begin{array}{l}\text { Data between parentheses are percentages; } * \text { - statistically significant } \\
\text { data; pt- patient; CE- coronary endarterectomy; ECC- extracorporeal } \\
\text { circulation; AMI- acute myocardial infarction; ARF- acute renal failure; } \\
\text { ICU- intensive care unit. }\end{array}$} \\
\hline
\end{tabular}

\begin{tabular}{|cc|}
\hline $\begin{array}{c}\text { Table III - Risk factors for mortality related to coronary } \\
\text { endarterectomy through multivariate analysis with estimation of } \\
\text { odds ratio }\end{array}$ \\
\hline Variables & Odds ratio \\
\hline Female sex & 3.111 \\
Diabetes mellitus & 3.482 \\
Left main disease & 3.767 \\
Acute myocardial infarction & 3.546 \\
Previous revascularization & 4.295 \\
Ejection fraction 35\% & 5.890 \\
\hline
\end{tabular}

\begin{tabular}{|lccccc|}
\hline \multicolumn{7}{|c|}{ Table IV- Relation between the site of endarterectomy and morbidity } \\
and mortality
\end{tabular}

\section{Discussion}

The era of direct operations on coronary arteries for the treatment of coronary heart disease ${ }^{4}$ started in 1957 with the performance of direct endarterectomy by Bailey et al ${ }^{1}$. With the appearance of extracorporeal circulation and spread of myocardial revascularization through venous grafts, the technique of direct endarterectomy remained out of use for several years.

The concept of complete myocardial revascularization gained strength in cardiology because of the higher incidence of late deaths, recurrence of angina, myocardial infarction, and reoperations in patients treated incompletely ${ }^{5,6}$. Improvement in the results of myocardial revascularization caused by a larger experience, by the development of methods of myocardial protection, and by the use of the internal thoracic artery has allowed its application in patients

\begin{tabular}{|lccc|}
\hline \multicolumn{4}{|c|}{$\begin{array}{c}\text { Table } \mathbf{V} \text { - Relation between the type of graft used in myocardial } \\
\text { revascularization associated with coronary endarterectomy and } \\
\text { morbidity and mortality }\end{array}$} \\
\hline Graft & Venous & Arterial & $\mathrm{p}$ \\
\hline IAoB & $43(14.93)$ & $4(8.33)$ & 0.222 \\
Arrhythmia & $98(34.03)$ & $13(27.08)$ & 0.344 \\
AMI & $41(14.24)$ & $6(12.5)$ & 0.748 \\
Death & $30(10.42)$ & $1(2.08)$ & 0.100 \\
Total & 288 & 48 & - \\
\hline
\end{tabular}

Data between parentheses are percentages; IAoB- intraaortic balloon; AMI- perioperative acute myocardial infarction. 
with diffuse coronary heart disease, which was earlier considered a surgical contraindication. In addition, technological development has contributed to delay in operative indication because of pharmacological or percutaneous treatment, or both. Therefore, the presence of patients with advanced atherosclerotic disease with a still viable myocardium is increasingly more frequent, in whom the only way of effectively preserving function is through removal of the atheromatous plaque, followed by revascularization with venous or arterial grafts, or both.

The use of coronary endarterectomy, however, is still controversial mainly because of lack of uniformity in its indications and controversial results, according to studies in the literature, most of which are retrospective. A first issue to be approached is the definition of the ideal patient and the concept of diffuse atherosclerotic disease of coronary arteries. Livesay et $\mathrm{al}^{3}$ have considered necessary the presence of occluded arteries with multiple stenoses and diffuse distal involvement. Christakis et $\mathrm{al}^{7}$ have added the presence of arteries perfusing viable myocardium with reversible ischemia, documented by scintigraphy with thallium or analysis of regional contraction on echocardiogram, or both. The contraindications for the procedure consisted of arteries with diameter smaller than $1 \mathrm{~mm}$ irrigating myocardial areas of fibrosis secondary to previous infarcts and extremely calcified vessels ${ }^{8,9}$. Souza et al ${ }^{10}$ divide the indications of coronary endarterectomies into planned, when the procedure may be planned through preoperative coronary angiography, and necessary, when during operation the surgeon finds a previously attractive artery for myocardial revascularization but only coronary endarterectomy makes the procedure feasible.

The frequency of coronary endarterectomy varies with the medical center. Some groups perform it in a liberal manner without a careful analysis of each case, where it may represent up to $42 \%$ of the myocardial revascularizations performed ${ }^{11}$. Our incidence of $3.73 \%$ reflects our conservative trend in regard to the procedure.

Another relevant issue is the importance of cardiac risk factors for the disease that affects millions of people in the entire world, but in this case it seems to manifest in a much more intense manner with significant repercussions when clinically or surgically treated ${ }^{12}$. When comparing conventional myocardial revascularization with that associated with coronary endarterectomy, Livesay et al $^{3}$ identified in the latter group a higher incidence of male patients, of patients with diabetes mellitus, with ventricular dysfunction, and a higher number of arteries undergoing revascularization per patient. The higher incidence of postoperative acute myocardial infarction was related to incomplete obstruction (stenosis $<90 \%$ ) of the coronary artery undergoing endarterectomy ${ }^{13}$.

Brenowitz et al ${ }^{12}$ have defined the following as risk factors for multiple endarterectomy: age $>70$ years, reoperation, insulin-dependent diabetes mellitus, female sex, and severe ventricular dysfunction. They also established a relation between the higher number of these factors and mortality. In patients undergoing multiple coronary endarterectomy and in the presence of 2 or more of these factors, the index was $26.9 \%$, and in those with no risk factor it was $1.7 \%$. The application of this index was reproduced by Salerno et al $^{8}$, but not by other authors ${ }^{14}$.

Therefore, determination of the risk factors related to mortality of myocardial revascularization associated with coronary endarterectomy is extremely important to establish the most favorable cases. In our study, we identified as risk factors for in-hospital mortality the following: female gender, diabetes mellitus, left main disease, acute myocardial infarction, previous myocardial revascularization, and ejection fraction $<35 \%$. We found a relation between a higher number of these risk factors and the chance of in-hospital death.

From the technical point of view, endarterectomy may be manual or with the aid of carbon dioxide to detach the atheromatous plaque, but the latter has been currently abandoned. The procedure should be complete, and therefore it is more difficult to perform in the left coronary artery because of its great number of branches and because of its smaller diameter. Arteriotomy size varies according to the facility of plaque detachment and may extend distally. Serial incisions may be performed to avoid blind tractions and intimal lesions. Therefore, because of the difficulty in accessing the branches of the left coronary artery, the resulting arteriotomy may be very long ${ }^{14}$.

The methods of reconstruction of the wide arteriotomy comprise the following: primary suture, wide anastomosis with venous grafts, and arterioplasty with fragments of the saphenous vein isolated or followed by myocardial revascularization with arterial grafts ${ }^{15,16}$.

More frequently, coronary endarterectomy is performed in a single manner, but some authors ${ }^{17}$ report its performance in two, three, and even seven arteries. Other authors believe a relation exists between the number of endarterectomies and the greatest morbidity and mortality, but this could not be reproduced in our study nor in others ${ }^{7,13,17}$.

The procedure usually requires a greater period of extracorporeal circulation and anoxia ${ }^{7}$. Therefore, myocardial protection is mandatory. The method to be employed is, however, another point of controversy. Most authors prefer blood cardioplegia ${ }^{2}$.

The site of endarterectomy, morbidity, and mortality is a controversial point. The right coronary artery was the first and is still the most frequently used artery because of the greater technical simplicity of the procedure in this artery and the relatively low risk. Brenowitz et al ${ }^{12}$ introduced the use in the left arterior descending artery, but they reported a higher immediate mortality, as did others ${ }^{3,11,13}$. These data could not be reproduced by Minale et al ${ }^{18}$ or by us, where a similar incidence was shown. We believe that the risk factors and performance of complete myocardial revascularization are more important than sim ply the site where coronary endarterectomy is performed.

Likewise, the type of graft used in coronary endarterectomy is a matter of controversy. The use of venous grafts is historical and few reports ${ }^{15,19}$ have shown experience with arterial grafts. Beretta et al ${ }^{20}$ in a comparative analysis between the saphenous vein and the internal thoracic artery 
found in the latter group lower mortality and incidence of acute myocardial infarction, a higher permeability of grafts at short- and long-term follow-up, and a higher symptomatic relief in the late follow-up. In our experience, despite the predominant use of venous grafts, we did not find significant differences between the type of graft used and immediate morbidity and mortality.

The main cause of failure in the postoperative period of coronary endarterectomy is acute myocardial infarction, which is directly related to thrombosis in the site of endarterectomy. This is the reason why some groups have routinely used platelet antiaggregating agents and anticoagulants, with significant changes in the prognosis ${ }^{21}$. Other causes of early occlusion of grafts are the incomplete removal of atheromatous plaques, intimal flap obstructing tributary vessels, conditions of low cardiac output, technical problems of the anastomosis, and inadequate myocardial protection. Postoperative frequency of acute myocardial infarction has ranged from 5 to $25 \%$, with an associated mortality ranging from 0 to $15 \%$. In our experience, these values were $13.6 \%$ and $5 \%$, respectively.

The short-term results of coronary endarterectomy vary according to the study, reflecting variability in indications and operative techniques, as more recent studies ${ }^{7,13,17}$ have shown a significant improvement in results. Most studies, however, show a higher incidence of acute myocardial infarction, immediate mortality ${ }^{8}$, and a lower patency of the grafts performed in arteries undergoing endarterectomy, in relation to those where this resource was not used. The study by Livesay et $\mathrm{al}^{3}$ has analyzed the early and late evolution of 3,369 patients undergoing coronary endarterectomy, as compared with another group of 27,095 patients, in whom myocardial revascularization was not associated with coronary endarterectomy, during a period of 14 years. These authors have found a higher mortality (4.4\%), a higher incidence of postoperative acute myocardial infarction (5.4\%), and a higher incidence of cardiac arrest (3.5\%) in the group undergoing coronary endarterectomy as compared with that undergoing only myocardial revascularization.

Some authors ${ }^{7,14,17,22-24}$, however, report in-hospital mortality and patency of venous grafts similar for both groups. Larock et $\mathrm{al}^{22}$, with some differences in group homogeneity, have found a higher incidence of perioperative acute myocardial infarction, including impairment of the segmentary contractility assessed by myocardial scintigraphy with thallium. Christakis et al ${ }^{7}$, adopting strict criteria for indication, have prospectively studied 317 patients undergoing coronary endarterectomy as compared with 911 patients undergoing conventional myocardial revascularization with documented homogeneity between both groups. They have found a similar incidence of inhospital deaths $(3.2 \%$ and $3.8 \%)$, acute myocardial infarction $(6 \%$ and $5.5 \%)$, low cardiac output syndrome $(15.1 \%$ and $12.6 \%$ ), and use of intraaortic balloon ( $4.5 \%$ and $6 \%$ ). The authors have attributed these results to the strict se- lection of patients and the large experience with the technique.

Late survival ranges from $71 \%{ }^{13,17}$ to $90 \%$ after 5 years ${ }^{7}$, being comparable to that of the group undergoing conventional myocardial revascularization. Higher late mortality was observed in patients with acute myocardial infarction prior to surgery ${ }^{13}$, and also with advanced age and ventricular dysfunction ${ }^{12}$, reflecting the more aggressive nature of the disease.

Sequential anatomicopathological studies have demonstrated that, in cases of failure after endarterectomy, an accelerated process of myointimal proliferation occurs followed by atherosclerosis in a second plane ${ }^{25,26}$.

Livesay et $\mathrm{al}^{3}$ have found a small increase in the risk of mortality ( $2.9 \%$ per year) and in late complications in the long-term. The clinical evolution and prognosis, however, were similar to those of patients undergoing only myocardial revascularization. Patency of the grafts did not differ from that of coronary endarterectomy, being around $75 \%$ in 29 months. These data were reproduced by Goldstein et al ${ }^{9}$, who have found late permeability of $64 \%$ in 19 months.

On the other hand, Minale et al ${ }^{18}$ found different results when studying patency and changes in segmentary contractility after performing 728 coronary endarterectomies. Patency of the arteries undergoing endarterectomy was much lower than that of the arteries where this procedure was not used ( $45 \%$ versus $73.8 \%$ ). These data agreed with maintenance of anginal symptoms and worsening in functional class. Segmentary contractility improved in $35 \%$ to $45 \%$ of the previously hypokinetic and akinetic areas, and worsening of segmentary contractility happened in $24 \%$ of the normal areas, reflecting a greater risk of contractile deterioration and a certain degree of subclinical perioperative acute myocardial infarction. Therefore, they postulate that this procedure should be limited to patients with unstable, critical, irresponsive clinical findings, limited to arteries that irrigate the left ventricular posterior wall with mild ventricular dysfunction.

In conclusion, resurgence of coronary endarterectomy as an adjunctive of myocardial revascularization is a strong concept that has gained impetus through the technological development related to cardiac surgery, providing a significant improvement in its results, comparable to those of conventional myocardial revascularization. When performed in an indiscriminate manner in diffuse atherosclerotic disease, a higher in-hospital mortality occurs, related to perioperative acute myocardial infarction. The risk factors identified in this study are important components related to a poorer evolution and should be considered in surgical indication. Coronary endarterectomy should be used whenever possible in selected patients in a programmed manner to promote myocardial revascularization.

\section{Acknowledgments}

We thank Ms. Carine Sovalli for the statistical analysis. 


\section{References}

1. Bailey CP, May A, Lemmon WM. Survival after coronary endarterectomy in man. JAMA 1957; 164: 641-6.

2. Loop FD. Resurgence of coronary artery endarterectomy. J Am Coll Cardiol 1988; 11:712-3.

3. Livesay JL, Cooley DA, Hallman GL, et al. Early and late results of coronary endarterectomy. Analysis of 3,369 patients. J Thorac Cardiovasc Surg 1986; 92: 649-60.

4. Mueller RL, Rosengart TK, Isom OW. The history of surgery for ischemic heart disease. Ann Thorac Surg 1997; 63: 869-78.

5. Lawrie GM, Morris GC, Silvers A. The influence of residual disease after coronary bypass on the 5 year survival rate of 1274 men with coronary artery disease. Circulation 1982; 66: 717-23.

6. Jones EL, Craver JM, Guyton RA, et al. Importance of complete revascularization in performance of the coronary bypass operation. Am J Cardiol 1983; 51: 7-12.

7. Christakis GT, Rao V, Fremes SE, Chen E, Naylor D, Goldman BS. Does coronary endarterectomy adversely affect the results of bypass surgery? J Card Surg 1993; 8: 72-8.

8. Salerno PR, Dinkhuysen JJ, Chacur P, et al. Técnica e resultados da endarterectomia de artéria coronária. Rev Bras Cir Cardiovasc 1994; 9: 152-8.

9. Goldstein J, Cooper E, Saltups A, Boxall J. Angiographic assessment of graft patency after coronary endarterectomy. J Thorac Cardiovasc Surg 1991; 102: 53945 .

10. Souza LCB, Paulista PP, Sousa JEMR, et al. Endarteriectomia eletiva e revascularização do miocárdio. Arq Bras Cardiol 1983; 41: 327-34.

11. Qureshi SA, Halim MA, Pillai R, Smith P, Yacoub MH. Endarterectomy of the left coronary system. Analysis of a 10 year experience. J Thorac Cardiovasc Surg 1985; 89: 852-9.

12. Brenowitz JB, Kayser KL, Johnson D. Results of coronary artery endarterectomy and reconstruction. J Thorac Cardiovasc Surg 1988; 95: 1-10.

13. Djalilian AR, Shumway SJ. Adjunctive coronary endarterectomy: improved safety in modern cardiac surgery. Ann Thorac Surg 1995; 60: 1749-54.

14. Sommerhaug RG, Wolfe SF, Reid DA, Lindsey DE. Early clinical results of long coronary arteriotomy, endarterectomy and reconstruction combined with multiple bypass grafting for severe coronary artery disease. Am J Cardiol 1990; 66: 651-9.

15. Ladowski JS, Schatzlein MH, Underhill DJ, Peterson AC. Endarterectomy, vein patch, and mammary bypass of the anterior descending artery. Ann Thorac Surg 1991; 52: 1187-9.

16. Aranki SF. A modified reconstruction technique after extended anterior descending artery endarterectomy. J Card Surg 1993; 8: 476-82.

17. Brenowitz JB, Kayser KL, Johnson WD. Triple vessel coronary artery endarterectomy and reconstruction. Results in 144 patients. J Am Coll Cardiol 1988; 11: 706-11.

18. MinaleC,Nikol S,Zander M, Uebis R, Effert S, Messmer BJ.Controversial aspects of coronary endarterectomy. Ann Thorac Surg 1989; 48: 235-41.

19. Gill IS, Beanlands DS, Boyd D, Finlay S, Keon WJ. Left anterior descending endarterectomy and internal thoracic artery bypass for diffuse coronary disease. Ann Thorac Surg 1998; 65: 659-62.

20. Beretta L, Lemma M, Vanelli P, et al. Coronary open endarterectomy and reconstruction: short and long-term results of the revascularization with saphenous vein versus IMA-graft. Eur J Cardiothorac Surg 1992; 6: 382-7.

21. Cheseboro JH. Effect of dipyridamole and aspirin on late vein-graft patency after coronary bypass operations. N Engl J Med 1984; 310: 209-14.

22. Larock MP, Burguet W, Grenade T, et al. Usefulness of thromboendarterectomy in association with coronary artery bypass grafting. Am J Cardiol 1987; 60: 1025-9.

23. Kamath ML, Schmidt DH, Pedraza PM, et al. Patency and flow response in endarterectomized coronary arteries. Ann Thorac Surg 1981;31:28-35.

24. Asimakopoulos G, Taylor KM, Ratnatunga CP. Outcome of coronary endarterectomy: a case-control study. Ann Thorac Surg 1999; 67: 989-93.

25. Walley VM, Byard RW, Keon WJ. A study of the sequential morphologic changes after manual coronary endarterectomy. J Thorac Cardiovasc Surg 1991; 102: 890-4.

26. Kragel AH, McItosh CM, Roberts WC. Morphologic changes in coronary artery seen late after endarterectomy. Am J Cardiol 1989; 63: 757-9. 